\title{
Guerra, mobilização e escravidão no Brasil e nos Estados Unidos
}

Peter M. Beattie*

Izecksohn, Vitor. Slavery and War in the Americas: Race, Citizenship, and State-Building in the United States and Brazil. Charlottesville: University of Virginia Press, 2014.

Talvez o maior elogio que possa ser feito a um livro seja: "Por que ninguém fez um estudo desta natureza antes?" Entendo que Slavery and War in the Americas cabe nesta categoria de livro; mas o potencial do objeto de pesquisa de Vitor Izecksohn já fora previsto uma geração antes, pelo historiador James M. McPherson, em Battle Cry of Freedom: the Civil Era (Nova York: Ballentine Books, 1988). Como Izecksohn mesmo observa (p. 4), McPherson, baseado na literatura secundária, comentou que ao lado do povo paraguaio, que perdeu cerca de $50 \%$ de sua população adulta durante a Guerra da Tríplice Aliança (segundo algumas estimativas), os esforços da Confederação do Sul dos Estados Unidos pareciam fracos, pois os rebeldes só perderam $5 \%$ da sua população antes de se render. Dito isso, é possível afirmar que a resposta do historiador brasileiro ao chamado de McPherson é original, pois ele esco- lheu um ponto de comparação diferente e, a meu ver, mais interessante ainda. Em vez de examinar os exércitos da Confederação e do Paraguai, ele enfoca as dificuldades que os exércitos vitoriosos, da Uniáo dos Estados Unidos e do império brasileiro, enfrentaram para mobilizar soldados para o front. No final das contas, foram esses dois exércitos que tomaram parte na consolidação de suas naçôes, apesar da força de tradiçóes e ideologias que favoreciam o poder local - especialmente quando se tratava dos sistemas de defesa. Em ambos os casos, as autoridades dos governos centrais tiveram que negociar com as autoridades locais para extrair soldados, açóes que provaram ser insuficientes para as demandas dos conflitos. Os dois governos centrais chegaram ao ponto em que se tornara necessário mobilizar escravos libertos como soldados, a fim de fornecer o volume de tropas necessário para o sucesso. Os líderes nacionais, dessa maneira, consideravam a integridade territorial como um princípio fundamental, e, por isso, decidiram lutar por uma vitória total sobre seus adversários. Enfim, o livro resenhado fornece a mais extensa comparação entre a Guerra Civil Americana (1860-1865) e a Guerra

\footnotetext{
* Doutor em História da América Latina pela Universidade de Miami, East Lansing, MI, Estados Unidos. professor de História da Universidade do Estado de Michigan. E-mail: beattiep@msu.edu.
} 
da Tríplice Aliança (1864-1870) produzida até agora, e por isso merece a atençáo não só de especialistas, mas de pesquisadores interessados na história comparativa em escala mundial.

Por que, até agora, ninguém aceitou o desafio de McPherson? A resposta é simples: as dificuldades que trabalhos de história comparativa implicam para o historiador, principalmente quando se insiste na utilização de fontes primárias, são enormes. Aliás, outra característica original do livro de Izecksohn é seu ineditismo, já que se baseia em sistemática pesquisa arquivística, ocorrida em ambos os lados do Equador. O resultado, portanto, é um dos mais instigantes trabalhos de história comparativa produzido nos últimos anos, talvez desde o livro de Charles Degler, Neither Black Nor White: Slavery and Race Relations in Brazil and the United States (Madison: University of Wisconsin Press, 1971), que, como o trabalho de McPherson, foi baseado em fontes secundárias.

As complicaçóes e o tempo demandado pela pesquisa empírica além do Equador não são os únicos obstáculos que um historiador comparativo enfrenta para realizar um projeto como Slavery and War in the Americas. A historiografia da Guerra da Tríplice Aliança abrange quatro países e está em plena fase de expansão, enquanto os trabalhos sobre a Guerra Civil nos Estados Unidos são numerosos e o campo náo demonstra sinais de decréscimo. Dominar a literatura em si já é um grande desafio, que Izecksohn passou anos digerindo. Por esses esforços, o autor merece reconhecimento, e esperançosamente, o trabalho inspirará outros jovens pesquisadores nos Estados Unidos, no Brasil e em outros países, a seguir seus passos.

Um dos principais pontos do livro de Izecksohn é a maneira como ele insere a história da mobilizaçáo de soldados nos contextos históricos do desenvolvimento das guerras e das políticas nos Estados Unidos e no Brasil. Em ambos os casos, havia bastante apoio popular inicial para as guerras e muitos cidadãos se voluntariaram para seguirem para os fronts. Ou seja, o patriotismo romântico associado à ideia do cidadão-soldado inspirou muitos homens a pagarem o seu tributo do sangue sem coerção. Contudo, o otimismo gerado pelos chamados às batalhas duraria pouco tempo, $\mathrm{e}$ quando ficou claro que as guerras não terminariam rapidamente, fator somado às notícias das baixas, doenças e condiçốes onerosas que a soldadesca enfrentava, a popularidade das mobilizaçóes caiu grandemente e o número de voluntários diminuiu de modo considerável. A partir de então, tanto o governo do Brasil como o da Uniáo contemplaram maneiras coercitivas para completar suas fileiras de praças e oficiais.

$\mathrm{Na}$ União, foi implantado um sistema de conscriçáo por sorteio, mas nem por isso se proibiu a substituição dos designados por outros ou o pagamento de isenção pecuniária. No Brasil, por sua vez, o governo imperial exigiu cotas das províncias, proporcionalmente às suas populaçóes, chamando membros $\mathrm{da}$ Guarda Nacional, normalmente protegidos do recrutamento, para servirem ao Exército. Em ambos os casos, os sistemas de recrutamento não forneceram os números de recrutas necessários, e, por isso, decidiu-se pela mobilização de escravos e ex-escravos. 
Izecksohn narra exemplos específicos de conflitos entre cidadãos e autoridades locais e centrais em várias comunidades, desde a região da Nova Inglaterra até o Meio-Oeste americano. Uma das características de seu texto, aliás, é a maneira admirável como o autor costura exemplos específicos, que envolvem indivíduos humildes e poderosos, sem perder a capacidade de síntese concisa requerida para contextualizar esses episódios.

Um exemplo é o caso do advogado William A. Pors, de Port Washington, Wisconsin, nomeado por seu governador para servir de comissário do sorteio militar em um dos distritos da cidade, em 1862. Ali, um grupo de homens e mulheres marchou, naquele ano, até o fórum, para, finalmente, desembrulhar uma bandeira, exclamando: “No Draft!" Aquelas pessoas também ameaçaram Pors: "Se ele for ao fórum, será um homem morto." Pors, por sua vez, tentou acalmar o espírito dos manifestantes, pedindo a eles que se dispersassem, sem sucesso. Quando o grupo viu a caixa do sorteio militar, eles atacaram os condutores dela e a destruíram. Depois disso, espancaram William Pors, que conseguiu escapar e entrar na agência dos correios, onde encontrou proteção de outras autoridades. Esses atos de resistência ao sorteio, ocorridos por todos os estados do norte, em pequenas cidades como Port Washington, e em outras maiores, como Nova York, enfraqueceram a habilidade de mobilizar recrutas utilizando o novo sistema, uma proposta que supostamente teria dado mais autoridade ao governo central.

Tratando do Brasil, Izecksohn também incluiu exemplos interessantes. Um deles é o do jovem escravo Carlos, cujo mau comportamento levou seu dono a vendê-lo como recruta para o exército imperial. Mesmo assim, apesar da alta demanda, os inspetores das forças armadas o rejeitaram por seu mau estado de saúde. Ao perceber que seu senhor o venderia como escravo destinado às lides do campo, Carlos se evadiu, sendo capturado mais tarde no Rio de Janeiro. Ativando seus procuradores na corte, mais uma vez o senhor de Carlos ofereceu seu escravo como recruta, tarefa para a qual finalmente foi aceito - e, entáo, seu dono recebeu US\$ 640.00, lucrando US\$ 180.00 na operação (p. 128-129). Aqui, Izecksohn sucintamente ilustra como as açóes de um escravo, seu senhor e as autoridades do governo negociaram o recrutamento militar, a alforria e a política de venda de escravos neste período singular. Entretanto, como o próprio autor enfatiza, o recrutamento de cativos ou homens livres para a Guerra da Tríplice Aliança exigiu a cooperação das lideranças e dos potentados locais. Senhores que não queriam vender seus escravos não foram obrigados a fazê-lo; chefes políticos protegeram efetivamente seus clientes (homens livres) de bandos de recrutadores, especialmente nos anos centrais da mobilização.

Como o título da obra indica, a escravidão é um tema privilegiado no livro. Dois dos cinco capítulos enfocam essa comparação, que constitui uma das contribuiçôes mais interessantes do volume. Dessa forma, Izecksohn argumenta, de uma maneira distinta dos historiadores da Guerra Civil nos Estados Unidos até agora, que foi o fracasso das tentativas de implementar a conscrição 
que levou o governo da Uniáo a formar regimentos segregados, compostos por homens de cor, para lutar. Até o momento da formalização dessa medida, a ideia de ser cidadão-soldado havia sido considerada um privilégio dos brancos. Mas o elevado número de baixas e o ressentimento que a conscrição criou entre a população branca da União fez com que a mobilização de homens de cor parecesse mais aceitável à maioria nortista.

Diferentemente do Brasil, todavia, o exército da Uniáo manteve a segregação racial dos regimentos, regra seguida até a Guerra da Coreia (1950-1953). A envergadura desta mudança não deve ser negligenciada: ela foi fundamental para assegurar tanto a vitória da União quanto a abolição da escravidáo. Mesmo que os direitos à cidadania para homens de cor tenham sido sufocados depois da Reconstrução (1865-1877), o serviço militar desses contingentes virou uma contradição e um fator-chave que por fim abriu espaço para as lutas políticas em prol de direitos civis e integração no século XX.

Quanto à Guerra da Tríplica Aliança, Vitor Izecksohn ainda demonstra que foram as açôes do maior aliado brasileiro, a Argentina, que levaram o governo imperial a recrutar cativos para lutar contra o Paraguai. A instabilidade política da república argentina levou seu presidente, Bartolomé Mitre, a deixar o comando das forças aliadas e voltar à capital, Buenos Aires. Junto de Mitre foram seus soldados, e o Brasil teve que extrair ainda mais recrutas para sustentar a guerra. Uma carta do ministro da Guerra ao presidente da Província do Rio Grande do Sul, em 1867, demonstrou a conexáo direta entre a retirada das forças argentinas e a necessidade de mobilizar escravos (p. 147).

Diferentemente dos Estados Unidos, onde movimentos sociais a favor da abolição e a opinião pública pressionavam o governo de Lincoln em favor do uso de escravos como soldados, no Brasil a decisão de mobilizá-los foi feita a portas fechadas, como uma necessidade de segurança nacional. No caso brasileiro, portanto, tal fato não era ligado a campanhas abolicionistas, onde a experiência militar seria um laboratório de cidadania para os homens de cor.

$\mathrm{O}$ autor de Slavery and War in the Americas utiliza estudos de caso para refletir sobre interpretaçóes mais amplas que abrangem os resultados dessas duas guerras. Por exemplo, ele argumenta que o Brasil conseguiu vencer a Guerra da Tríplice Aliança sem grandes modificaçôes econômicas e sociais, como novos (e onerosos) impostos, ou um surto de industrialização, ou ainda a abolição da escravidão. De maneira contrastante, o governo e a economia da Uniáo parecem muito mais próximos de um caso de guerra total, que estimulou a industrialização, destruiu escravidão como uma maneira de derrotar o inimigo e aumentou o poder do governo central. Assim, a Guerra Civil dos Estados Unidos abriu espaço para realizar políticas que os estados do norte favoreciam por décadas: tarifas para bens industriais importadas, imposto de renda, decisóes econômicas mais centralizadas para desenvolver a infraestrutura de transportes e indústrias etc. Nesse sentido, para Izecksohn, a comparação oferece a oportunidade de criticar interpretaçóes que dão pouca ênfase a Guer- 
ra Civil como um exemplo de guerra total (p. 175-176).

Este livro, portanto, oferece muito a leitores não especialistas, assim como aos especialistas, historiadores militares ou não. A prosa é clara e sucinta, e a leitura é prazerosa. Espero que a obra atraia muitos leitores e que não tenhamos que esperar mais uma geração para que trabalhos de semelhante ambição e alcance sejam levados a cabo. 